Paper Presented to the "7th Annual Meeting of the Southeast Regional Health Physics Society Chapters," Charleston, South Carolina, May 3-5, 1990

CONF-9005435--1

DE93 002123

\title{
ALARA PRACTICES TO MINIMIZE OCCUPATIONAL RADIATION EXPOSURE FROM CONTAMINATION AT COMMERCIAL NUCLEAR POWER PLANTS
}

J. Reyes-Jimenez and L. Tsoukalas

The University of Tennessee and Oak Ridge National Laboratory Department of Nuclear Engineering 315 Pasqua Engineering Building Knoxville, Tn 37996-2300

(615) $974-7569$

May 3-5, 1990 
Paper Presented to the "7th Annual Meeting of the Southeast Regional Health Physics Society Chapters," Charleston, South Carolina, May 3-5, 1990

\title{
ALARA PRACTICES TO MINIMIZE OCCUPATIONAL RADIATION EXPOSURE FROM CONTAMINATION AT COMMERCIAL NUCLEAR POWER PLANTS
}

\author{
J. Reyes-Jimenez and L. Tsoukalas \\ The University of Tennessee and Oak Ridge National Laboratory \\ Department of Nuclear Engineering \\ 315 Pasqua Engineering Building \\ Knoxville, Tn 37996-2300 \\ (615) 974-7569
}

\begin{abstract}
Many systems in a commercial nuclear power plant carry or process radioactive sources. The design of such systems includes a wide spectrum of factors and mechanisms that help mitigate the spread of radioactive contamination in the unlikely event of an accident. In practice however events of a more routine nature like small leaks and and maintenance activities have proven to be significant contributors of occupational radiation exposure(ORE). This paper examines various aspects and techniques utilized in the design of nuclear plant systems in light of their operational history, and proposes improvements that could help minimize the exposure of plant personnel to radiation.
\end{abstract}

Commercial nuclear power plants undergo scheduled and non-routine maintenance during their lifetime. This includes the replacement or system components that are in direct contact with radioactive sources. During maintenance there may be liquid spills or leaks that contribute to an undesirable spread of radioactive contamination. 
A number of design features are incorporated into the operating and maintenance procedures of a plant in order to keep the ORE to a minimum level; these are collectively embodied in the ALARA principle (As Low As Reasonably Achievable). ALARA typically involves minimizing the time spent in contaminated areas, minimizing the number of radiation workers, provide adequate shielding and crud and source reduction. This paper presents an "intelligent" optimization tool and concrete suggestions that can help improve existing ALARA programs and can contribute to the design of future plants. Using techniques from the field of Artificial Intelligence it allows for a simulation of non-routine maintenance activities and suggests possible strategies that will result in the minimum ORE. 

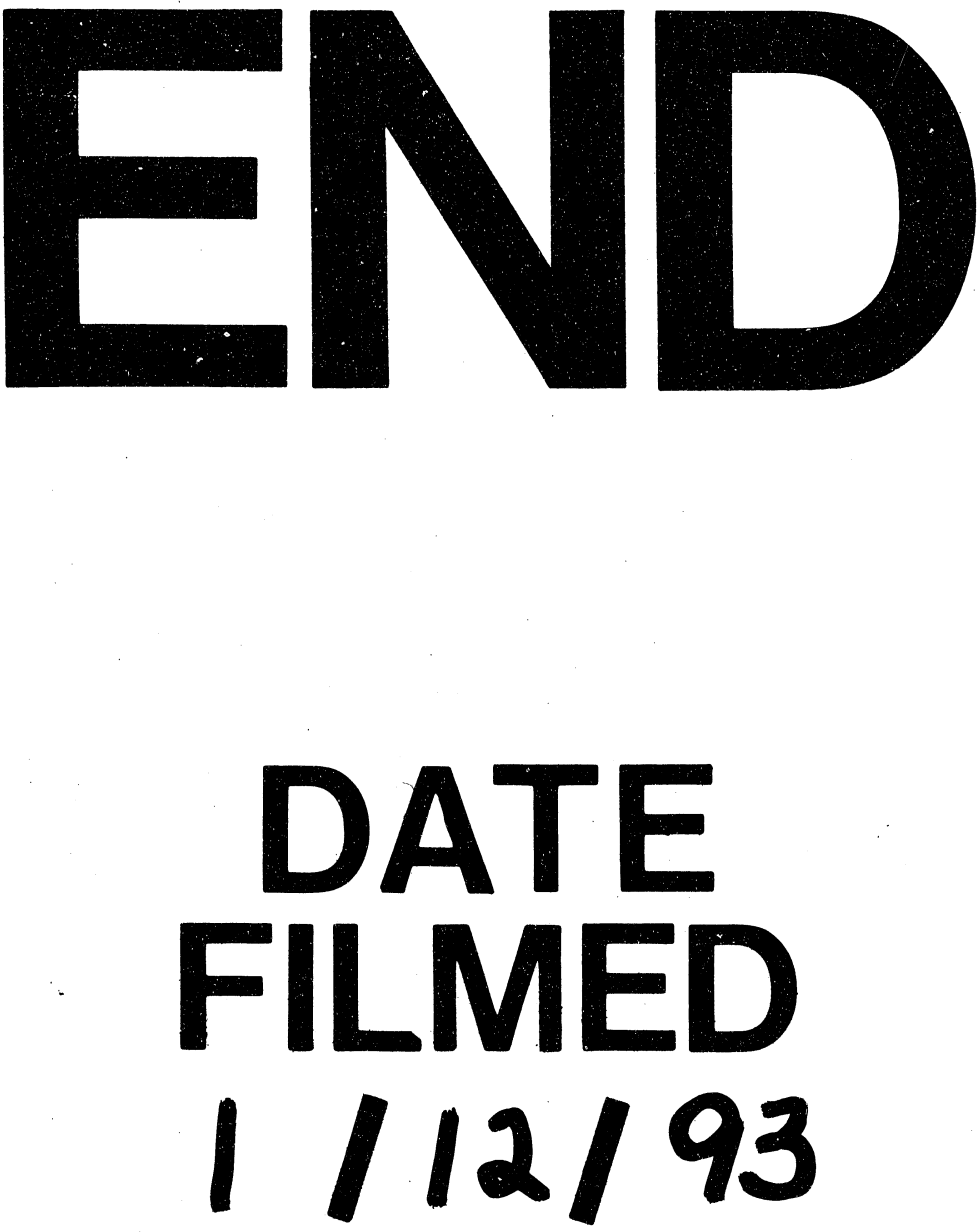
